\title{
Chapter 13 \\ Unintended Environmental Impacts at Local and Global Scale_-Trade-Offs of a Low-Carbon Electricity System
}

\author{
Maryegli Fuss and Lei Xu
}

\begin{abstract}
The focus on expanding the sector coupling and binding the electricity system and end-user sectors like the transport and industry bring attention to environmental trade-offs. Otherwise, unintended environmental impacts could potentially impede the transformation process. Given that, this paper aims to identify and discuss environmental burdens that should require government attention. For that, the approach of coupling Life Cycle Assessment with the electricity market model (ELTRAMOD) is presented. Results show that the large impact on land use occupation as a regional issue requires attention due to diversified permitting mechanisms and eligibility criteria for solar fields among European member states. Metal and ozone depletion bring the challenge that transformation processes need attention on global limits related to finite resources and fugitive losses of anthropogenic substances.
\end{abstract}

\subsection{Introduction}

Fossil-based electricity systems meet, among other criteria, the security conditions of a power outage for many energy-intensive sectors (e.g., residential and tertiary) in Europe for many years. The transition toward low-carbon energy sources (European Commission 2018c) focuses on expanding sector coupling. Now the critical issue is to bind the electricity system and the two largest fossil fuel combustion sectors, transport, and industries (cf. Part III and IV). The challenge going forward is to maintain the security of supply of the electricity sector (including transport and industry sectors) and at the same time to achieve specific decarbonization targets (cf. Chapter 2).

The embedded carbon emissions are becoming more and more discussed between researchers. For instance, there is a debate about the biases of a clean conceptual approach for greener mobility through electric vehicles when the energy in-use source is an oil or coal-based power plant (Clarke 2017; Egede et al. 2015; Holloway 2019).

M. Fuss $(\bowtie) \cdot$ L. Xu

Karlsruhe Institute of Technology (KIT), Karlsruhe, Germany

e-mail: maryegli.fuss@kit.edu 
Indeed, there is no doubt that the electricity system has to undergo a radical transformation as the leading sector to reshape the entire European energy system (European Commission 2018c). Under these circumstances, the electricity system became the core sector that requires an in-depth analysis in the REFLEX project.

Among the REFLEX scenarios (cf. Chapter 2 and Poganietz et al. 2017; Zöphel et al. 2019), combustion emissions affecting climate change such as $\mathrm{CO}_{2}, \mathrm{CH}_{4}$, $\mathrm{N}_{2} \mathrm{O}$, and so on, have the potential to be reduced significantly, if wind and solar technologies are deployed on a very large-scale in Europe. Moreover, decarbonizing the electricity sector will facilitate significant reductions in carbon emissions due to industry, transport, residential, and tertiary sectors. Part III and Part IV of this book describe how carbon targets could be achieved within the scope of the REFLEX scenarios.

Developments aiming at reducing greenhouse gas emissions from the electricity sector may nevertheless cause increases in other kinds of environmental impacts. Costa-Campi et al. (2017) also stress that energy policies usually focus on the political economy dimension, which could bring conflicts with the goal of environmental protection. It is necessary to be aware that the transition of the energy system depends on many techno-economic features such as the massive penetration of renewable technologies that are still not in place in some countries and the need for low-carbon emission fuels like natural gas (cf. Chapters 10 and 11). All these developments could drive critical environmental impacts on the European scale (i.e., local effects), but also globally due to the reach of supply chains. Although discussions at the political level have expanded to include broader sustainability-related considerations, imposing protection conditions for ecosystems and human health, for example, Europe still gears its policy toward carbon-based benchmark regulation exclusively (European Commission 2019a).

The objective of the present Chapter is to identify and discuss unintended environmental burdens based on the envisaged REFLEX scenarios that require further policy action. Unintended environmental burdens are impacts that are driven by a critical problem that could impede a smooth transition to the decarbonized European energy system. Based on the methodological framework developed in the REFLEX project (Brown et al. 2017; Brown et al. 2019), this paper applies the model coupling approach (cf. Chapter 3). It focuses on the process of coupling Life Cycle Assessment (LCA) with the bottom-up electricity market model (ELTRAMOD), the chosen energy system model for this study. The model coupling between LCA and ELTRAMOD brings the advantage of quantifying a full range of environmental impacts and therefore the possibility to discuss environmental trade-offs of the three REFLEX scenarios, Mod-RES, High-RES decentralized, and High-RES centralized (cf. Chapter 2 and 10).

The structure of this paper is therefore as follows:

- Describing the model coupling approach to analyze scenarios for the electricity system (Sect. 13.2); 
- Describing and discussing the unintended environmental consequences of the European low-carbon electricity system at member states level and globally (Sect. 13.3);

- Conclusions and formulating policy implications (Sect. 13.4).

\subsection{Developing the Model Coupling Approach to Identify Environmental Trade-Offs}

For the REFLEX project, three fundamental aspects are taken into consideration in electricity production systems:

1. The need for new infrastructure: The transformation of the electricity sector is a gradual process that will require, among other developments, new infrastructure to facilitate deployment of large-scale renewable technologies that are not in place yet.

2. Innovative technologies: They are technologies for exploiting intermittent energy sources, e.g., wind and solar. Wind turbines and solar photovoltaic cells provide examples of how industries are rapidly changing. Many of them have similar competitive perspectives, such as to offer the most efficient product with low maintenance costs, and low resource demand (Froese 2019; Gandenberger 2018).

3. Less emission-intensive fossil fuels: The European Union has always taken necessary precautions in the area of fuel supply, especially concerning fossil energy resources. For instance, there is an ongoing focus on natural gas supply in the EU policy (Correljé 2016).

LCA and ELTRAMOD have a different objective function. While LCA is focused on environmental impacts modeling, ELTRAMOD is an electricity market model (cf. Chapter 10). This study follows the detailed procedures described by Xu et al. (2019). Firstly, inputs for the LCA model are based as closely as possible to the REFLEX scenarios (Chapter 2) in line with (1) and (2). Secondly, the LCA model is adapted to the technology groups used by ELTRAMOD. ELTRAMOD considers conventional and renewable technologies and a low-carbon group representing installed capacities of fossil fuel-fired carbon capture and storage (CCS) technologies (cf. Chapter 10), bringing attention to a policy aimed at securing fuel supply (3).

This study recognizes several challenges and barriers to producing LCA results that match public policy development (Hellweg and Milà i Canals 2014; Seidel 2016). For instance, transparency and accurate inventories are often questionable among non-practitioners. To establish a common understanding, the most significant inputs and adjustments for the model coupling are presented below. 


\subsubsection{Describing Relevant Input Parameters for the LCA Model in Context of the REFLEX Scenarios}

Transparency of input data for the LCA model is important to support robust conclusions. In the REFLEX project, identification of specific technology types is the starting point for ensuring that future supply needs (e.g., resources and fuels) are considered. The challenge is to include scenario-based considerations in establishing life cycle inventory for future energy technologies over their entire lifetime (including extraction of raw materials, manufacturing of new technologies, transportation and installation, generation of electrical power to the grid and end-of-life).

The future market share of innovative and conventional technologies is a parameter directly connected to the REFLEX scenarios. The study of Viebahn et al. (2015) provided a technological roadmap and bandwidth extrapolations based on a search of all renewable energy technologies existing in energy scenarios in Germany. Additionally, this study analyzed possible future developments of renewable energy technologies based on literature and expert knowledge. However, the market share parameter defined by Viebahn et al. (2015) is only applied in this study for wind and solar technologies that are currently accepted or emerging on the market. Technologies on the laboratory scale are not included. Wind power technologies are represented in the LCA model by four different turbine types (asynchronous generators, electrically excited direct drive, permanent magnet, and superconductor high-temperature) and solar power is represented by two types of photovoltaic cells (crystalline cells and thin-film cells).

The LCA model and ELTRAMOD have common techno-economic parameters. The approach for parameter harmonization in REFLEX (Fuss et al. 2018) required coordination of techno-economic characteristics of technologies (e.g., installed capacity, lifetime, and efficiency) to increase the consistency among the models. Techno-economic parameters provide, for example, the possibility to quantify resource demands for each technology according to the capacity expansion paths assumed in ELTRAMOD.

Figure 13.1 shows generic inputs and outputs for the transition of the electricity system in Europe. Although the goal is to make the electricity sector cleaner and provide better environmental conditions in Europe, attention should be paid to consequences at a global scale too. It should be noted that outputs of the transition should achieve goals according to the European commitment within the sustainable development goals (European Commission 2019c) such as to safeguard life on land and secure good health and well-being.

Figure 13.1 also shows fuels, resources, and entire technologies imported to Europe from the global market. This study assumes that these resources, fuels and technologies are produced in the global market. This assumption is based on the fact that the EU is in favor of free trade and does not make exceptions to this for energy technologies and related markets (European Commission 2018b). With respect to fuels, the LCA model considers the exploration (or cultivation for biomass) and production at supplier location as a first stage. The supplier countries commitment 


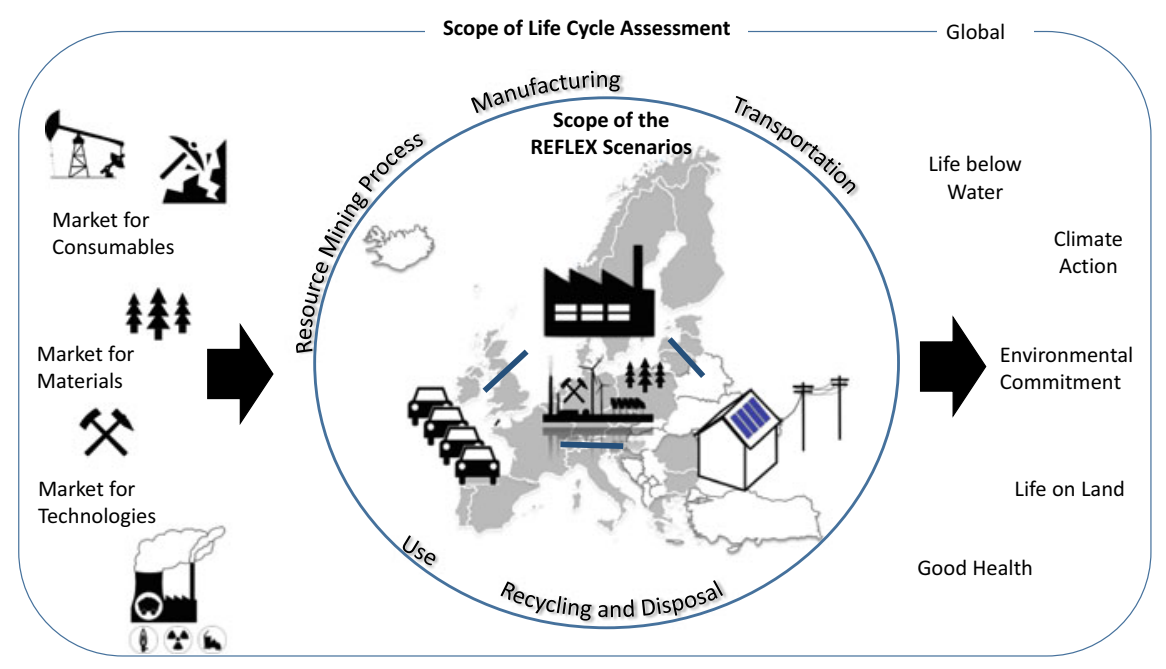

Fig. 13.1 Example of inputs and outputs required for electricity production (Source Own illustration)

ends after the transportation of the fuel to local and large-scale power plant distribution in Europe, the second stage considered in the LCA modeling. Due to significant uncertainties about future developments, it is assumed that the share of the global suppliers (i.e., European supplier leading countries) does not change in any of the REFLEX scenarios.

The entire inventory analysis makes use of the ECOINVENT 3.3 database, which provides well-documented foreground process data (Wernet et al. 2016). For each emerging technology, a new inventory database is established based on resource inputs and electricity demand for production. Details of the life cycle inventories for all technologies considered and the respective ECOINVENT data processes used are available in Brown et al. (2019).

\subsubsection{Coupling the Results of ELTRAMOD and the LCA Model to Determine Policy Implications}

Figure 13.2 illustrates the procedure used in this study from coupling the results of ELTRAMOD through to the identification of relevant policy implication. Step 1 consists of coupling the described LCA model (Sect. 13.2.1) with results for electricity generation mix generation produced by ELTRAMOD. Equation 13.1 summarizes the model coupling calculation method: 


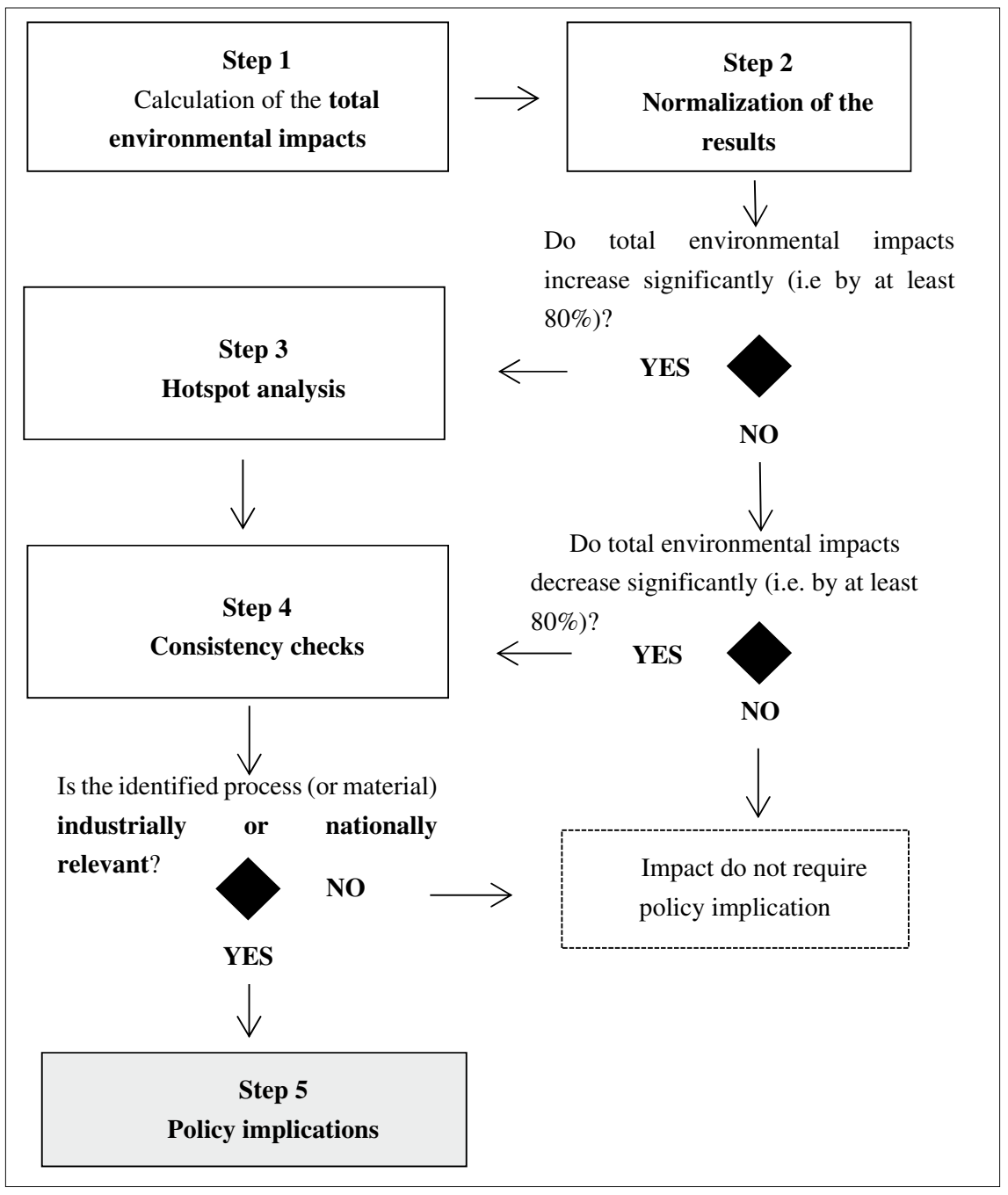

Fig. 13.2 Systematized procedures for extracting LCIA results for policy guidance (Source Own illustration)

$$
Z_{n, t}=\sum_{T=1}^{n} L C I A_{T, n, t} * E T_{T, t}
$$

where $Z_{n}$ is the total environmental impact in category $n$ over the life cycle of an energy technology group of all modeled countries, i.e., EU-27, Norway, Switzerland, United Kingdom, and Balkan countries in period $t$ measured in the respective unit, e.g., in case of metal depletion, $t F e_{e q}$ (ton iron equivalent), $L C I A_{T, n, t}$ is the environmental impact of an energy technology group in period $t$ measured in the respective 
unit, e.g., $t F e_{e q}$, per TWh. $E T_{T, t}$ equals the electricity generation of the energy technology group in period $t$ in TWh. For instance, $E T_{\text {wind }}$ represents the group of specific technologies $T$ as previously described (e.g., synchronous generators, and asynchronous generators).

Step 2 consists of normalization to evaluate 18 different impacts categories according to the RECIPE life cycle impact assessment (LCIA) method (Goedkoop et al. 2012) that is used in the REFLEX project. In this step, the calculated results in each scenario and the respective temporal cases are divided by the base year (2014). In this way, it becomes possible to screen for the most relevant impacts for each scenario. The screening analysis aims to identify those environmental impacts that overtook the threshold defined by the modelers. The threshold of $80 \%$ reduction or increase was chosen. The value of the index is comparable to the climate target. Hence, unintended environment burdens are identified when the environmental impacts increase significantly (by at least $80 \%$ ).

In-depth analysis of unintended environmental burdens is performed in step 3 . The largest contributors (drivers) to these impacts are analyzed in terms of the most critical technology from the electricity production mix, life cycle stage, processes, and flows.

The level of uncertainty is one of the barriers to trust in LCA results, as mentioned by non-practitioners and decision makers (Seidel 2016). Sensitivity analyses, mapping characterization, and classification factors applied or not in the RECIPE method, double-checking with different LCIA methods were conducted as part of step 4 of the method (i.e., consistency checks).

Up to step 4, the used procedure follows the usual procedures that are taken in LCA modeling to derive robust conclusions (Zampori et al. 2016). Step 5 is added exclusively for this study. The objective of step 5 is to assess the findings of the LCA model from the perspective of current policies and national and industrial priorities as considered in the literature.

A comparison with current policies supports the discussion of identified drivers (e.g., technology or flow) is the trade-off that can impede the achievement of the climate target if no intervention is made.

The policy implications should be seen as precautionary information aiming to raise awareness about potential trade-offs and related environmental consequences without further policy intervention.

\subsection{Unintended Environmental Consequences of the European Low-Carbon Electricity System}

According to the 2014-2050 REFLEX scenarios, results are presented for the total environmental impacts due to the total electricity generation in EU-27, Norway, Switzerland, United Kingdom, and Balkan countries (Chapters 2 and 10 and Zöphel et al. 2019) for a given temporal case. The absolute environmental impacts are 
presented (instead of the normalized results) for better comprehension of the findings discussed. They are introduced at an aggregate level as a final output of the schematic workflow, instead of describing the findings for each step (c.f. Figure 13.2) and each generation technology (Chapter 10). The overall impacts due to the REFLEX scenarios (step 1 and 2) are presented in Brown et al. (2019).

\subsubsection{Environmental Impacts at Local Scale and the Challenges for European Member States}

Land use is an environmental trade-off arising for the low-carbon electricity systems in the REFLEX scenarios. Figure 13.3 shows the absolute land use for the development of the overall electricity generation according to the envisaged scenarios.

Increasing demand for ground-mounted photovoltaic (PV) is responsible for increases in land use for all scenarios. According to Fig. 13.3, High-RES scenarios show a dramatic increase in land use, by a factor of nearly five over the baseyear, reaching $32,630 \mathrm{~km}^{2} \cdot \mathrm{a}$ (High-RES cen) and $33,724 \mathrm{~km}^{2} \cdot \mathrm{a}$ (High-RES dec). In particular, between the years 2020 to 2040, the impact on land use occupation is a consequence of the changing mix of technologies used for electricity generation. While coal-based generation is replaced (among other technologies) by the increasing capacities of ground-mounted PV (and wind energy), land use impacts

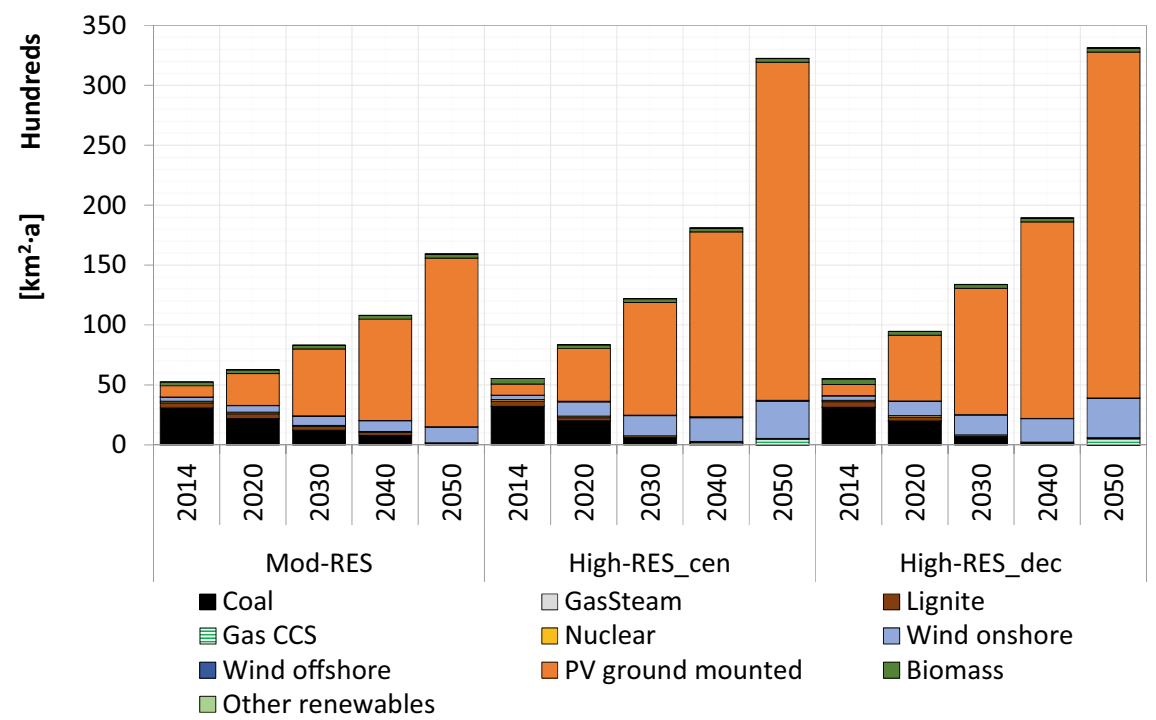

Fig. 13.3 Major technologies contributing to the land use impact of the overall electricity generation in EU-27, Norway, Switzerland, United Kingdom, and Balkan countries (Source Own illustration) 
increase. In the period 2040-2050, land use impact doubles due to measures aiming to achieve the target to electrify the transport and industry sectors.

For comparison: the direct land use for coal-based generation is $4.5 \mathrm{~km}^{2} / \mathrm{TWh}$ compared to an average of $47.8 \mathrm{~km}^{2} / \mathrm{TWh}$ for ground-mounted PV. Indirect impacts due to coal surface mining are not taken into account. In contrast, the estimated land use of $2.5 \mathrm{~km}^{2} / \mathrm{TWh}$ for wind technologies is relatively low.

In the RECIPE impact assessment method, the land use category "land use occupation" avoids any other trade-offs for land used for food and the conservation of the ecosystem. The results above represent this category. It is assumed that no land transformation from one status (e.g., forest) to the other (e.g., agricultural land) will occur. Therefore, competitions, which still might happen as a consequence of land used for urban expansion or even a delay of restoration to the prior nature conditions, cannot be excluded (Goedkoop et al. 2012).

Although land use seems not to be a significant environmental problem, the results indicate that $28,864 \mathrm{~km}^{2}$ of land (equivalent to over $70 \%$ of the total area of Switzerland) would be required for solar fields in 2050 in the High-RES decentralized scenario. The requirement is similar for the High-RES centralized scenario, as shown in Fig. 13.3. This is because the electricity mix is very similar in both scenarios (Zöphel et al. 2019). In any of the cases (centralized or decentralized), it should be noted that $56 \%$ of the total area requirement for solar electricity generation is potentially aimed for solar fields between 2040 and 2050.

As part of the European SET-Plan, the deployment of ground-mounted PV will increase in European member states (European Commission 2018c). Italy, France, and Spain are the EU countries with the highest potential for technology due to proper climate conditions, among other criteria. The European standard classification, defines land use division into agricultural land, forest and "other" (this category includes built-up areas, roads and other transportation features, barren land, or wasteland) (CIA World Factbook 2018). If the installed capacity (demand) are taken into account according to High-RES decentralized scenario, it will require over $9 \%$ of the "other" category of land in Italy, $12 \%$ in Spain, and $4 \%$ in France. Those three countries have diversified permitting mechanisms and eligibility criteria for ground-mounted PV plants. In France, implementation conditions for groundmounted PVs are under discussion where bonus could be accepted if wasteland (e.g., landfills, industrial brownfield, and polluted area) would be taken (Bozonnat 2018). However, the French Act on Energy Transition (France 2015) stands only on the market segment for PV rooftop installations. Meanwhile, in Italy, large solar fields require a process authorization that is still not clearly defined. Within the authorization process, the Italian government aims to minimize agriculture land losses and guarantee their aesthetic green power system (Bellini 2019). Ground-mounted PV fields are well accepted in Spain. The country eliminated all constraints that could impede the deployment of renewable technologies in the national legislation since 2014 (Morales 2018). The free-deployment legislation could be attractive for investors. Therefore, Spain is facing the highest urban growth rate in the EU (URBACT 2019). Competition in Spain between urban development and space for 
ground mounted solar PV could be a future challenge, especially since there is only a small amount of land in the category "other."

However, Italy, Spain, and France are examples of countries where regulations could impede the transition to renewable energy based on ground-mounted PV plants.

\subsubsection{Resource Depletion in REFLEX Mitigation Scenarios as a Backdrop of Global Trade Uncertainty}

Metal depletion, owing to the research focus on innovative technologies (cf. Sect. 13.2), calls for in-depth analysis of the availability of finite resources. At the same time, the shift to natural gas-based carbon capture and storage electricity generation requires attention to ozone depletion due to emissions of ozone-depleting substances in natural gas supply chains. In light of these considerations, metal and ozone depletion impacts are presented in the following sections.

\subsubsection{Metal Depletion}

Another consequence of the electrification of the industry and transport sectors to reach the climate targets (cf. Chapter 6, 7 and 10), is the trade-off on metal depletion. Figure 13.4 shows that regardless of the scenario or year, metal depletion increases due to increased solar and wind energy generation. The high share of wind and solar electricity generation in the High-RES decentralized scenario (to achieve, for instance, the demand for hydrogen production in industry and transport in 2050, cf. Zöphel et al. 2019) increases the metal depletion impact to over $290 \%$ compared to the year 2014. Meanwhile, in the Mod-RES and High-RES centralized scenario, the growth is about 75 and $235 \%$ for the same period, respectively.

Metal depletion is estimated to be $19,530 \mathrm{tFe}$ eq $/ \mathrm{TWh}$ for wind onshore, $25,900 \mathrm{tFe}_{\mathrm{eq}} / \mathrm{TWh}$ for PV rooftop compared to $4,140 \mathrm{MtFe}_{\mathrm{eq}} / \mathrm{TWh}$ for nuclear power plants. Chromium steel, low-alloyed steel, reinforced steel (for towers, rotors, and nacelles) as well as copper for connecting wires together contribute to over $90 \%$ of the metal depletion for onshore wind generation. In spite of the fact that industries are seeking to minimize the demand for silver in crystalline PV manufacturing (ITRPV 2018), rooftop PV generation indicates the highest metal depletion impact where the major contributors are copper (58\%), gold (7\%), steel (4\%), and silver (1\%). Among those metals, recycling activities are intensively done only for steel.

In a sensitivity analysis, the possibility of steel recycling was taken into account. The results shown in Fig. 13.4 are based on the assumption that all metals are primary resources, i.e., obtained directly from mining activities. Nowadays, about $80 \%$ of steel is recycled globally (BIR 2018). With a hope that steel recycling could reach $90 \%$ until 2050, the burdens of metal depletion for electricity production in the High-RES centralized scenario can be reduced by $40 \%$ according to the sensitivity 


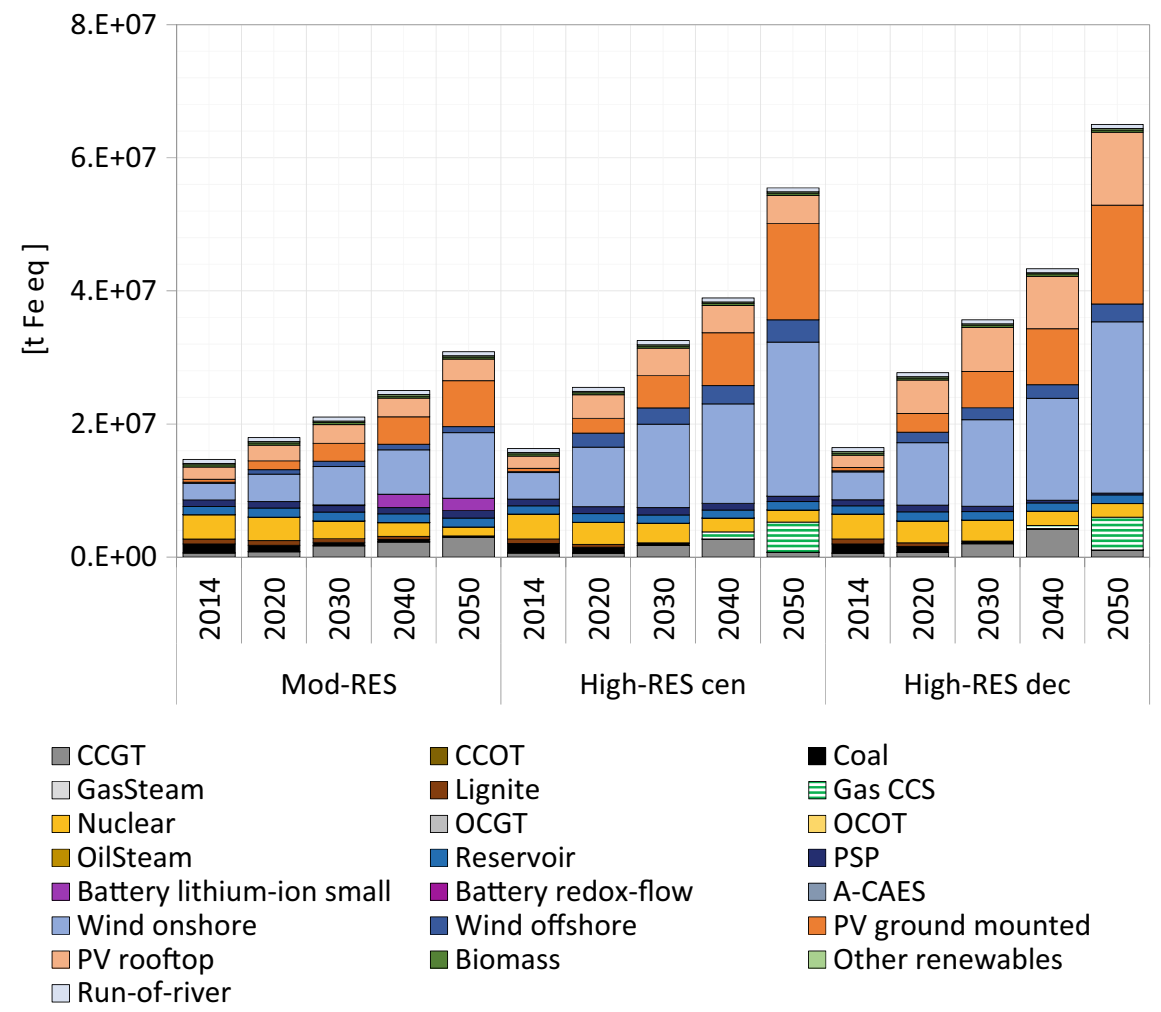

Fig. 13.4 Major technologies contributing to metal depletion impacts due to total electricity generation in the EU-27, Norway, Switzerland, United Kingdom, and Balkan countries. Abbreviations: CCGT (combined cycle gas turbine), PSP (pumped-storage power plants), Gas CCS (gas carbon capture and storage) (Source Own illustration)

analysis. It should be noted that recycling indexes for other metals are lower than $50 \%$ (e.g., copper) or even non-existent in the EU (e.g., silver) due to small quantities in electronic facilities (Hagelüken et al. 2016).

The challenge regarding metal depletion is that metals are non-renewable resources comparable to fossil fuels. The environmental impact indicates the reduction of availability of a specific group of resources (commodities). The assumption lies in the mining costs as the dominant and consistent factor between dissimilar metals in the RECIPE method (Goedkoop et al. 2012).

In the model applied, innovative wind and solar technologies (Sect. 13.2.1) are distinguished from the conventional ones according to the new resources required for their manufacture. Ten metals are additionally included for these technologies in this study, namely, neodymium, praseodymium, dysprosium, gadolinium, and cobalt for emerging wind turbines and cadmium, selenium, tellurium, gallium, and indium for thin-film solar cells. In the consistency checks (step 4, cf. Figure 13.2), it is observed 
that those metals were not assessed in the results presented in Fig. 13.4. The main reason is the missing characterization factors in the RECIPE method.

Following the same assumptions as presented in the RECIPE method, for example, the weighting factor of platinum is taken for neodymium. Platinum represents the highest mining costs with over 11,000 USD/kg in the RECIPE method (Goedkoop et al. 2012). Neodymium is rare and often hard to find, which would therefore be comparable to platinum. It is a rare earth metal belonging to a group of 15 different elements which together represent $5-10 \%$ of a mineralized rock (monazite). It is extracted from open-pit mining mainly located in China. Nowadays, due to several challenges such as environmental issues, illegal mining, and export, the Chinese government are implementing policies such as mining quotas (Mancheri et al. 2019). Neodymium is nevertheless an essential resource for wind turbines with high power output and large blade sizes (Vestas 2019). Taking the most ambitious REFLEX scenarios (High-RES scenarios) as an example, considering the framework conditions, the demand for neodymium alone would contribute to $95 \%$ of the total metal depletion for wind power. If neodymium would be included in the RECIPE method, it would lead to the greatest single inventory contribution in the metal depletion impact category.

Although the results for metal depletion are highly dependent on the technologies (Sect. 13.2.1) and resources previously described, there is no doubt that wind and solar technologies are highly competitive in the global market. Many European companies are strongly recognized on the market for wind technologies, such as Denmark's Vestas and Spain's Siemens Gamesa, which are behind China's Goldwind, the world's largest wind turbine companies (Froese 2019). Meanwhile, Chinese industries have taken the lead in photovoltaic manufacturing due to strengthened innovation efforts in the country (Gandenberger 2018). Thus, availability and access to the resources considered in this study will be a major factor to ensure the necessary commercial development and to achieve the envisaged targets for the transformation of the electricity system.

Secure access to resources and resource efficiency are objectives identified in the EU 2020 strategy (European Commission 2011). Nevertheless, metal depletion is a trade-off for climate targets as problems arise due to high metal demand (e.g., steel) and the high amount of non-recyclable metals.

\subsubsection{Ozone Depletion}

The High-RES scenarios show how high $\mathrm{CO}_{2}$ prices will potentially require lowcarbon energy sources (e.g., nuclear power plants) and accelerating the deployment of the natural gas generation with carbon capture and storage (CCS) from 2040 onwards (cf. Chapter 10). An outcome of these developments is an increase in ozone depletion impact, as shown in Fig. 13.5.

Ozone depletion brings consequences for humans globally (e.g., excess skin cancer incidence) because of ozone layer destruction through fugitive losses of anthropogenic substances (Goedkoop et al. 2012; Velders et al. 2000). One of the 


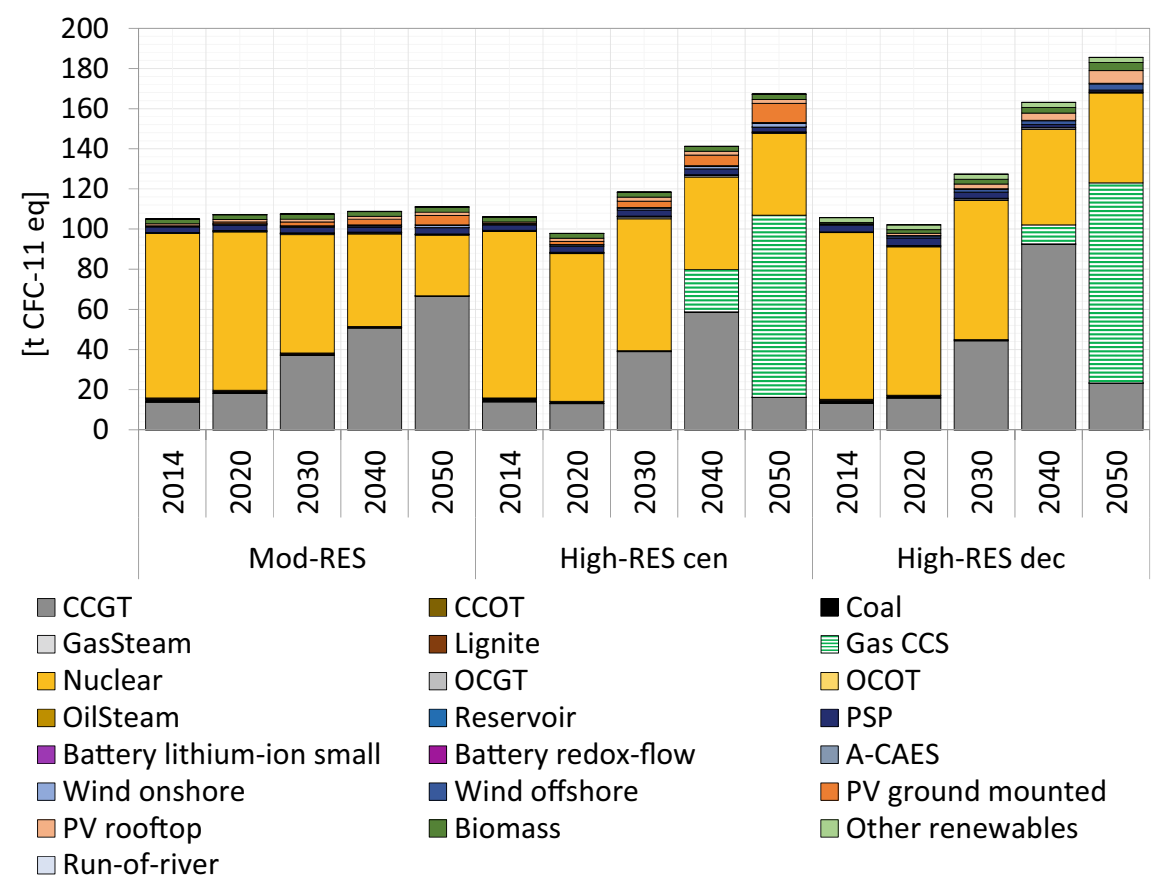

Fig. 13.5 Major technologies contributing to ozone depletion in overall electricity generation in the EU-27, Norway, Switzerland, United Kingdom, and Balkan countries (Source Own illustration)

global responsibilities assumed by the EU is the Montreal Protocol that aims to protect the ozone layer by identifying hotspots where ozone-depleting substances might occur (EEA 2018). With this consideration in mind, two aspects of the ozone depletion results from the analysis of the REFLEX scenarios are presented (cf. Figure 13.5):

- Mod-RES scenario (2014 vs. 2050): The magnitude of the ozone depletion impact remains approximately constant, but the contribution share is shifting according to the change in generation mix from nuclear to combined cycle gas turbine (CCGT).

- High-RES scenarios (2014 vs. 2050): The rapid increase of the ozone depletion impact is accompanied by the rise in power generation of natural gas CCS.

The transportation of natural gas, as fuel for CCGT and natural gas CCS generation, is the specific activity contributing to ozone depletion according to the life cycle phases connected to the supply chain. The identified problem arises due to leaks of methane and hydrocarbons in the pipelines from Russia, as the major natural gas supplier for Europe. Europe imports $40 \%$ of natural gas from Russia, 38\% from Norway, 11\% from Algeria, 4\% from Qatar, and others (Eurostat 2019). 
Transport of natural gas releases leakage nowadays (ICLG 2019; Healing 2018; Nasralla 2020). Pipeline leaks are a complex environmental problem for local supplier countries. Leakage of natural gas consists primarily of methane and ethane, and both are drivers for photochemistry reactions and non-linear interaction in the stratosphere-troposphere (Portmann et al. 2012; Velders 1997; Velders et al. 2000). Bromochlorodifluoromethane (Halon 1211) and Chlorodifluoromethane (HCFC-22) are two critical substances identified in the modeling analysis. These two substances are released in the stratosphere-troposphere due to other past and current industrial processes (Portmann et al. 2012). The concentrated amount of natural gas leakage may attack chlorine and bromide from Bromochlorodifluoromethane (Halon 1211) and Chlorodifluoromethane (HCFC-22) (Velders 1997; Portmann et al. 2012). Such reactions impede the future evolution of the ozone (Velders 1997; Portmann et al. 2012).

Additionally, the increasing demand for natural gas and continuous leakage problems can degrade regional air quality and are bad for human health (cf. Chapter 15, Velders et al. 2000). Moreover, the effects imposed on the supply chain of natural gas already bring new awareness that is connected to the problem of pipelines identified in this study. Among several issues, geopolitical changes are influencing the natural gas market (Correljé 2016) and can slow the pace of climate targets in Europe, if the electricity mix will be dependent on CCGT or gas CCS technologies. Furthermore, many Russian pipelines have exceeded their operational lifetime (Nasralla 2020). Thus, significant investments are needed to comply with new regulations, such as the installation of electromechanical corrosion protection of pipelines, technological communication facilities, leak identification, and warning systems (ICLG 2019; IEA 2006). Meanwhile, Norwegian companies are working on better sealing technologies because leakages are not visible in the stormy and cold North Sea by monitoring systems which leads to problems for the supply chain (Healing 2018). However, an environmental challenge exists for many European countries, especially Germany, that needs to import more natural gas as a substitute for the coal-based electricity generation.

Although industries and nations are already facing the challenge, it is still not clear how countries (exporter or importer) will divide the responsibility for judging the compliance to diminish pipeline leaks. Until no bilateral commitment is aimed, great demand for natural gas has the potential to enhance ozone depletion causing regional effects and trade-offs for the achievement of climate targets.

\subsection{Conclusions and Policy Implications}

The electrification of end-user sectors and the simultaneous decarbonization of the electricity system are ambitious targets for the European Union. This sector coupling approach is a key element in the transition to a fossil-free economy. From an environmental perspective, a successful sector coupling is highly dependent on the development of the electricity system. Moreover, the reduction of greenhouse gas emissions 
by $80 \%$ for the electricity sector requires, among other things infrastructure planning, availability of technologies that are ready at a convenient time and environmentally friendly low-carbon emission fuels. Otherwise, three environmental impacts, identified in this paper, could impede the transition process for a low-carbon electricity system. Land use requires infrastructure planning among EU member states with different regulations. The results concerning the assessment of metal depletion demonstrate that the transformation process to a low-carbon electricity system is highly dependent on the availability of metals (finite resources) to produce technologies for intermittent electricity generation. The outcomes of the analysis regarding ozone depletion highlight the potential effects of fugitive losses that affect anthropogenic substances (e.g., Halon 1211 and HCFC-22 identified in this study) and are an issue for global suppliers of natural gas. This impact additionally leads to the demand for further international agreements (such as the Montreal Protocol) to protect the ozone layer.

The results are created through the schematic work and method described in this study. They build upon the model coupling of LCA and ELTRAMOD to assess the REFLEX scenarios. The outcomes are highly interconnected to the assumptions made and the LCA modeling. Therefore, this study includes a methodological description to promote transparency and robustness to the results. However, the analysis of potential environmental impacts of the energy transition increase awareness and identify new research areas.

Through the LCA modeling, it is identified that the deployment of groundmounted PV technologies has a crucial environmental impact. Land use for groundmounted PV in the base year (2014) amounts to only 3\% of that required in 2050 for the High-RES decentralized scenario-950 $\mathrm{km}^{2}$ compared to $28,864 \mathrm{~km}^{2}$ (cf. Figure 13.3). Countries with best weather conditions for ground-mounted PV power plants (like Italy, Spain, and France) consider restrictions concerning aesthetic requirements as well as potential resident opposition (NIMBY — not in my back yard). Although data show, the availability of other lands for ground-mounted PV installation (cf. Section 13.3.1), society and legal systems could impede such developments. Considering these constraints would require a break-down of regulations and infrastructure planning among EU member states and continuous investment in research at local scales. Investment in research and innovation opens opportunities for solar energy. Hoffacker et al. (2017) present how PV systems enable techno-ecological synergies in the United States, for instance, the utilization of a reservoir power plant for solar electricity generation ("floatovoltaics") and PV systems integrated in agricultural landscapes (agro-photovoltaics). In Europe, few agro-photovoltaic projects have been implemented and still need to deal with agronomic challenges like the field management on crop production (Weselek et al. 2019).

A more tightly integrated Europe, not in political terms but rather with respect to technology development and supply markets, would help to address the challenges related to metal and ozone depletion. For instance, the transformation of the entire European electricity system depends mostly on the commitment of member states, where some countries will probably set up more ambitious targets than others. Consequently, these members will require a higher commitment to deploy innovative 
renewable technologies similar to those studied in this chapter, such as permanent magnet and superconductor high-temperature wind turbines. Contrary to the current free-market orientation on the openness of trade (European Commission 2018b), the proximity of renewable technology industries with the EU could bring advantages for both sides. In this regard, the EU could support even more local industries to address the fluctuation of resource prices and trade import tariffs, although Europe has one of the lowest trade import tariffs in the world (European Commission 2019b). On the other hand, industries could provide more information about how the required resources are affecting the global environment. Because the supply chain for crucial resources of wind technologies involves intense mining activities causing strong vulnerability due to regional impacts on the environment (Ballinger et al. 2020).

The assessment results presented in this study confirm that natural gas will be the most significant contributor to European energy security in the upcoming future, replacing oil and coal energy sources (Correljé 2016). Germany, for instance, has assumed a National Preventive Action Plan and Emergency Plan with regard to natural gas and has taken the responsibility to be the European business location for natural gas (European Commission 2018a). However, stockpiling of natural gas could be the most attractive alternative to guarantee desired fuel stocks, along the lines of a similar procedure adopted by Germany for petroleum (European Commission 2018a). Therefore, further commitments by supply and demand countries regarding global impacts (ozone depletion) would additionally create incentives between the natural gas sectors to promote dialogues and foster investments (e.g., renovation, research, and innovation) for an environmental friendly low-carbon fuel.

This study identifies and discusses policy implications related to three environmental trade-offs in the context of a low-carbon electricity system: land use occupation, metal depletion, and ozone depletion. Many contributing factors to the unintended environmental burdens (trade-offs) are technically known. However, the factors are still not discussed as an obstacle for the European electricity transition. The development of any strategy to deal with these environmental trade-offs should bring local industries, member states, and the EU together.

\section{References}

Ballinger B, Schmeda-Lopez D, Kefford B, Parkinson B, Stringer M, Greig C, Smart S (2020) The vulnerability of electric-vehicle and wind-turbine supply chains to the supply of rare-earth elements in a 2-degree scenario. Sustainable Production and Consumption 22:68-76. https://doi. org/10.1016/j.spc.2020.02.005

Bellini E (2019) Italy sets 2030 solar target of $50 \mathrm{GW}$, PV magazine. https://www.pv-magazine. com/2019/01/11/italy-sets-2030-solar-target-of-50-gw/ (Accessed 19 May 2019)

BIR (2018) World steel recycling in figures: 213-217. Bureau of International Recycling

Bozonnat C (2018) Ground-mounted PV plants: Ground-mounted PV plants: regulatory framework in France, France

Brown N, Ekener E, Fuss M, Xu L (2017) D6.1 Report on LCA-based framework. REFLEX project, REFLEX project report 
Brown N, Lindén D, Fuss M, Xu L (2019) D6.3 Social, environmental and external cost assessment of future energy technologies and future energy systems. REFLEX project report

CIA World Factbook (2018) Spain Land use. https://www.indexmundi.com/spain/land_use.html (Accessed 01 June 2019)

Clarke S (2017) How green are electric cars? The Guardian. https://www.theguardian.com/football/ ng-interactive/2017/dec/25/how-green-are-electric-cars (Accessed 06 May 2019)

Correljé A (2016) The european natural gas market. Curr Sustain Renew Energy Rep 3:28-34. https://doi.org/10.1007/s40518-016-0048-y

Costa-Campi MT, del Rio P, Trujillo-Baute E (2017) Trade-offs in energy and environmental policy. Energy Policy 104:415-418. https://doi.org/10.1016/j.enpol.2017.01.053

EEA (2018) The Vienna convention for the protection of the ozone layer: the Montreal protocol on substances that deplete the ozone layer. european environment agency

Egede P, Dettmer T, Herrmann C, Kara S (2015) Life cycle assessment of electric vehicles-a framework to consider influencing factors. Procedia CIRP 29:233-238. https://doi.org/10.1016/ j.procir.2015.02.185

European Commission (2011) A resource-efficient Europe: Flagship initiative of the Europe 2020 Strategy. $\operatorname{COM}(2011) 2$

European Commission (2018a) Germany National Energy and Climate Plans (NECPs). Brussels https://ec.europa.eu/energy/en/topics/energy-strategy-and-energy-union/governance-energyunion/national-energy-climate-plans (Accessed 25 May 2019)

European Commission (2018b) Report: EU trade agreements deliver on growth and jobs, support sustainable development: The better access to foreign markets negotiated by the EU benefits European companies, workers and consumers. http://trade.ec.europa.eu/doclib/press/index.cfm? id=1933 (Accessed 19 May 2019)

European Commission (2018c) The Strategic Energy Technology (SET) Plan, Brussels

European Commission (2019a) COM(2019) 175 final. Report from the Commission to the European Parliament, the Council, the European Economic and Social Commitee, the Commitee of the Regions and the European Investment Bank: Fourth report on the State of the Energy Union, Brussels

European Commission (2019b) Goods and services, Brussels. http://ec.europa.eu/trade/policy/acc essing-markets/goods-and-services/ (Accessed 1 June 2019)

European Commission (2019c) International cooperation and development. Building partnerships for change in developing countries. The Sustainable Development Goals

Eurostat (2019) Energy statistics. https://ec.europa.eu/eurostat/web/energy/data/database (Accessed 19 February 2019)

France (2015) Energy transition law. 2015-992. The French energy transition for green growth law

Froese M (2019) Vestas gains impressive lead as top wind-turbine manufacturer. https://www.win dpowerengineering.com/business-news-projects/vestas-gains-impressive-lead-as-top-wind-tur bine-manufacturer/ (Accessed 20 May 2019)

Fuss M, Brown N, Herbst A (2018) D1.3 Updated modelling parameters considering insights from Life Cycle approaches, REFLEX project report

Gandenberger C (2018) China's trajectory from production to innovation. Insights from the Photovoltaics Sector. Working Paper Sustainability and Innovation

Goedkoop M, Heijungs R, Huijbregts M, Schryver AD, Struijs J, van Zelm R (2012) ReCiPe 2008. A life cycle impact assessment method which comprises hamonised category indicators at the midpoint and endpoint level. First edition (revised)

Hagelüken C, Lee-Shin J, Carpentier A, Heron C (2016) The EU circular economy and its relevance to metal recycling. Recycling 1:242-253. https://doi.org/10.3390/recycling 1020242

Healing D (2018) Norwegian tech employs 'artificial magma' to stifle Alberta gas-well leaks. https://www.theglobeandmail.com/report-on-business/industry-news/energy-and-resources/ norwegian-tech-employs-artificial-magma-to-stifle-alberta-gas-well-leaks/article38330808/ (Accessed 23 March 2019) 
Hellweg S, Milà i Canals L (2014) Emerging approaches, challenges and opportunities in life cycle assessment. Science 344:1109-1113. https://doi.org/10.1126/science.1248361

Hoffacker MK, Allen MF, Hernandez RR (2017) Land-sparing opportunities for solar energy development in agricultural landscapes: a case study of the great central valley, CA, United States. Environ Sci Technol 51:14472-14482. https://doi.org/10.1021/acs.est.7b05110

Holloway H (2019) Analysis: just how green are electric vehicles? CO2-intensive battery production means emissions-free travel remains a mirage

ICLG (2019) Oil \& gas laws and regulations. https://iclg.com/practice-areas/oil-and-gas-laws-andregulations/russia (Accessed 29 April 2019)

IEA (2006) Optimising Russian natural gas: reform and climate policy

ITRPV (2018) International technology roadmap for photovoltaic including maturity report 2018

Mancheri NA, Sprecher B, Bailey G, Ge J, Tukker A (2019) Effect of Chinese policies on rare earth supply chain resilience. Resour Conserv Recycl 142:101-112. https://doi.org/10.1016/j.rescon rec.2018.11.017

Morales A (2018) Spain-The energy regulation and markets review, Madrid

Nasralla S (2020) Satellites reveal major new gas industry methane leaks. Sustainable business. Reuters. June, 262020

Poganietz WR, Kühn A, Reiter U, Fermi F (2017) Flexibility options in the context of future energy systems-some scenario-based reflections. REFLEX policy brief

Portmann RW, Daniel JS, Ravishankara AR (2012) Stratospheric ozone depletion due to nitrous oxide: influences of other gases. Philos Trans R Soc Lond B Biol Sci. May 5; 367(1593): 1256 1264. https://doi.org/10.1098/rstb.2011.0377

Seidel C (2016) The application of life cycle assessment to public policy development. Int J Life Cycle Assess 21:337-348. https://doi.org/10.1007/s11367-015-1024-2

URBACT (2019) The urban development in Spain—driving change for better cities. https://urbact. eu/spain (Accessed 25 May 2019)

Velders GJM (1997) Effect of greenhouse gas emissions on stratospheric ozone depletion. Bilthoven, Netherlands

Velders GJM, Slaper H, Pearce DW, Howarth A (2000) Technical report on stratospheric ozone depletion, Bilthoven

Vestas (2019) 4 MW Platform. https://www.vestas.com/en/products/4-mw-platform\#!product-str ategy (Accessed 26 Mai 2019)

Viebahn P, Soukup O, Samadi S, Teubler J, Wiesen K, Ritthoff M (2015) Assessing the need for critical minerals to shift the German energy system towards a high proportion of renewables. Renew Sustain Energy Rev 49:655-671. https://doi.org/10.1016/j.rser.2015.04.070

Wernet G, Bauer C, Steubing B, Reinhard J, Moreno-Ruiz E, Weidema B (2016) The ecoinvent database version 3 (part I): overview and methodology. Int J Life Cycle Assess 21:1218-1230. https://doi.org/10.1007/s11367-016-1087-8

Weselek A, Ehmann A, Zikeli S, Lewandowski I, Schindele S, Högy P (2019) Agrophotovoltaic systems: applications, challenges, and opportunities. A review. Agron. Sustain. Dev. 39:545. https://doi.org/10.1007/s13593-019-0581-3

Xu L, Fuss M, Poganietz WR, Schreiber S, Zöphel C, Jochem P, Brown N (2019) A systematic Environmental Assessment Framework for Energy System Analysis (EAFESA): an application to extract critical impacts of the future European electricity system, Cleaner Production Journal under review

Zampori L, Saouter E, Schau E, Cristobal J, Castellani V, Sala S (2016) Guide for interpreting life cycle assessment result. JRC Technical report 2016

Zöphel C, Schreiber S, Herbst A, Klinger AL, Manz P, Heitel S, Fermi F, Wyrwa A, Raczyński M, Reiter U, Möst D (2019) D4.3 Report on cost optimal energy technology portfolios for system flexibility in the sectors heat, electricity and mobility, REFLEX project report 
Open Access This chapter is licensed under the terms of the Creative Commons Attribution 4.0 International License (http://creativecommons.org/licenses/by/4.0/), which permits use, sharing, adaptation, distribution and reproduction in any medium or format, as long as you give appropriate credit to the original author(s) and the source, provide a link to the Creative Commons license and indicate if changes were made.

The images or other third party material in this chapter are included in the chapter's Creative Commons license, unless indicated otherwise in a credit line to the material. If material is not included in the chapter's Creative Commons license and your intended use is not permitted by statutory regulation or exceeds the permitted use, you will need to obtain permission directly from the copyright holder.

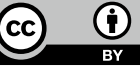

